speak of many ethers; and Jeans goes on to speak of an ether as belonging to each of us, which is indeed nonsense. He elaborates this absurdity on page 104, likening it to the carrying in a shower of rain, not indeed each his own umbrella, but our own rainbow.

All concrete things, in Jeans's philosophy, seem to vanish in a maze of abstractions. Even the waves of which everything is supposed to consist are thought of as abstractions before he has finished, though he has to admit that, as shown on Plate 2, page 42, they are real enough to be photographed. Needless to say, many of his illustrations are helpful; for example, his illustration of the welding together of different dimensions on page 99. Also his parable of the winding river, on page 147, though the moral is that an explorer ought not to be too confident about the direction in which the river is flowing, merely because it happens to be trending in one direction during his particular epoch. The book is full of happy and interesting applications and illustrations, and throughout is absorbingly interesting.

In so far as Jeans exhibits the tendency of modern physics in an idealistic direction, I have naturally no quarrel and welcome his support. Only I do not feel that his contention, that a mathematician alone can hope to understand the universe, is one that will stand scrutiny or substantiate itself. An artist might make another claim. That the Divine Mind can deal with abstractions more fully than any mathematician may be granted, but an Infinite Being has no limitations. His dealing with the abstract does not prevent His also dealing with concrete realities, or cause Him to abstain from attention to the utmost minutiæ. The absence of causation now postulated for the atoms and electrons, because we can only deal with them with any exactness in a statistical manner, is a sign of human limitation, and is not to be thought of as anything ultimate. The 'principle of uncertainty' is not a thing to pride ourselves on, except as a true representation of the present state of our knowledge. The fact that the quantum $h$ enters into it, means that there is more to be discovered. The Divine Artificer does not work with the calculus of probability. The free will of which we have experience is not to be explained as a result of physical indeterminism, though the present appearance of indeterminacy is a sufficient answer to those dogmatists who would wrest the findings of science to make such a thing as freedom impossible. It is useful in so far as it knocks the ground from under their feet, and leaves them without a leg to stand on.

Finally, on the question of the existence of an ether I appeal to the testimony of a greater even than Sir James Jeans. In his book "Sidelights on Relativity", Einstein says, on pages 16 and 17 :

"To deny the ether is ultimately to assume that empty space has no physical qualities whatever. . . . Newton might well have called his absolute space 'Ether',"

And on page 23 :

"Recapitulating, we may say that according to the general theory of relativity space is endowed with physical qualities; in this sense, therefore, there exists an ether. According to the general theory of relativity space without ether is unthinkable."

I entirely agree; whenever we leave mathematical abstractions and attempt to contemplate what is really happening, or happening in a physical sense, the discontinuity of matter must be supplemented by a continuous medium full of energy; which medium, I venture to say, is used as the instrument for causing and guiding all perceptible motions.

Oltver lodge.

Normanton House, Lake, Salisbury Plain, Nov. 10.

\section{Genetics, Mathematics, and Natural} Selection.

I $\mathrm{T}$ is a great honour to an author to have his book reviewed by the principal surviving advocate of the theories he has attacked. The only drawback to this honour is that the faculty of criticism, especially perhaps of impartial criticism, is very unequally developed in mankind, and, with the most honourable intentions, many misstatements or other slighter misrepresentations are likely to result. I should like to confine my remarks to six of these from the review of my book in NATURE of Oct. 18, which, I am sure, Prof. R. C. Punnett will be as glad as I to see decently buried. They can all be easily verified.

(a) "Dr. Fisher deplores the cleavage between the mathematical and the biological mind".

Actually, I deny the existence of such a cleavage and that although I am well aware that a few of the more conservative geneticists are feeling sore, and even anxious, about the increasing tendency of biologists to use mathematical methods. Such a feeling may be worthy of biological study, but is assuredly not characteristic of the biological mind, as I have exceptionally good reason for knowing.

(b) "the selective value of the mutation is regarded as in arithmetic proportion to its size, a view to which we fancy few biologists will be willing to subscribe."

My book is guiltless of any such assertion as this about mutations; on the contrary, an entire section (pp. 38-41) is given to examining why it is that, with highly adapted organs and organisms, the average selective advantage of mutations falls off with increasing magnitude.

As the author of the "presence and absence hypothesis ', it is natural that Prof. Punnett should dislike the theory of dominance I put forward; and as a poultry geneticist, that he should give undue prominence to the guess which, in the light of that theory, I have made as to the dominant genes found in the domesticated races of fowls. Such intensive interest might, however, have been accompanied by a higher level of accuracy :

(c) "Hence we must suppose that the mutational changes which give rise to dominant characteristics in domestic poultry show little or no influence in the wild form, that is, are either recessive or nearly so."

This may be Prof. Punnett's own inference; if it is intended to represent mine, as its context suggests, I must quote (p. 61) " not either completely dominant or completely recessive".

(d) "The mutant gene for crest must be regarded as having been brought in by the wild cock, in which it behaved as recessive to its uncrested allelomorph."

Nothing resembling this strange theory has been put forward by me.

Readers who remember the argument of Prof. Punnett's " Mimicry in Butterflies "will be interested in the following :

(e) " he seems rather uncomfortable about the way he disposes of Marshall, stating that we ' can neither assert that the Müllerian principle will work, nor that it will fail '."

Prof. Punnett must have been reading hurriedly; he has left out " so far as these arguments carry us ", from before the passage quoted (p. 153). The arguments in question are Marshall's, and Dixey's answer, which effectively neutralised Marshall's argument.

(f) " $\mathrm{He}$ strives hard, we think unsuccessfully, to get round it [Marshall's argument]; for in doing so he has to postulate an intermediate state enjoying the advantages of both."

This is one of the postulates of which I say (p. 153) " both are clearly extreme assumptions ; neither can be true generally". Naturally, this postulate does 
not enter into the argument, only fourteen lines long, which I put forward as definitely disproving Marshall's conclusion.

Finally, I should not like to seem ungrateful for the many kind remarks in Prof. Punnett's review, which, in view of the distaste he inevitably feels for my opinions, whether rightly or wrongly understood, I must regard as extremely generous. I hope, however, it may be possible to correct these misstatements without making Prof. Punnett think, as he seems to fear, that I am trying to ' convert' him to any new ideas, or even that I am here challenging the excellence of his reasons for rejecting them. R. A. Fisher.

Rothamsted Experimental Station,

Harpenden, Herts, Oct. 22.

WITH regard to Dr. Fisher's six charges of misrepresentation I am glad to avail myself of the editor's courtesy and to make a few brief comments. These may conveniently fall under Dr. Fisher's six headings.

(a) This seems to me to be a mere quibble. Dr. Fisher states that " the types of mind which result from training in mathematics and biology certainly differ profoundly" (p. viii), and in speaking of a cleavage between them I fail to see that I am seriously misrepresenting him.

(b) In discussing the question of a critical point below which a mutational change may or may not have selection value Dr. Fisher writes, "If a change of $1 \mathrm{~mm}$. has selection value, a change of $0.1 \mathrm{~mm}$. will usually have a selection value approximately onetenth as great" (p. 15) - a statement which seems sufficiently clear to serve as the basis of a " misrepresentation".

(c) So far as I am aware, no one has ever described a jungle fowl with a dominant domestic breed character, such as a crest, " not either completely dominant or completely recessive ". Indeed, it is difficult to know what meaning to ascribe to the word completely when applied to a dominant such as a crest. For in my experience it is easy enough to distinguish between a crested and an uncrested bird, and in this sense the crest is always completely dominant. But the size of the crest may vary greatly, according to the comb factors, and doubtless also to other factors in the genetical make-up of the bird. Perhaps on some future occasion Dr. Fisher will explain to us what he means when he qualifies "dominant" by " completely".

(d) On this point I am at a loss to know what to add. For my own sake and for that of the readers of Nature, I spent many hours in trying to translate Dr. Fisher's rather obscure account into language which should be intelligible to the ordinary geneticist ; and now I am told that I have evolved a strange theory which has not been put forward by him. But if the mutant gene for crest did not come in through the wild cock, where did it come from ? If it merely 'happened' in the domesticated form, Dr. Fisher's writings do not appear to bring us any nearer to a solution of the appearance of these dominant characters. For my own part, I should greatly welcome a clear account by Dr. Fisher-one intelligible to all of us mere geneticists - of what he considers to be the exact history of the crested gene, and of its manifestations, during the evolutionary history of a domesticated crested breed from the uncrested wild form.

(e) The "misrepresentation" here turns upon whether one accepts Dixey's answer as effectively neutralising Marshall's argument. Personally, I do not.

(f) On this point it is for the reader to judge between us.

R. C. Punnetr.

\section{The Behaviour of Methane Molecules and Argon Atoms in Collisions with very slow Electrons.}

IN a paper by E. Brüche on "Wirkungsquerschnitt und Molekülbau" 1 it is stated on p. 1105 that the curve which shows the variation of the effective crosssection of methane molecules with respect to slow electrons for different velocities of the electrons (we shall call these curves $Q \cdot \sqrt{V}$-curves, since the velocity is given in terms of $\sqrt{\text { volts) }}$ is of the argon type, namely, that as the velocity of the electrons decreases from 4 volts to 1 volt (that is, from $2 \sqrt{V}$ to $1 \sqrt{V}$ ) the $Q-\sqrt{\bar{V}}$-curve passes through a maximum and then rapidly sinks to a much lower value. This result was also obtained by R. B. Brode. ${ }^{2}$ In a later paper by C. Ramsauer and R. Kollath, ${ }^{3}$ Brüche's $Q-\sqrt{V}$-curve is extended to still lower electronic velocities (to about $0.39 \sqrt{V}$ ) and is found to pass through a minimum. We have now determined the $Q-\sqrt{V}$-curve for methane by Townsend's diffusion method and have also found that the absolute value of the effective cross-section $Q$ of methane molecules is very low, like that of argon, and that the $Q \cdot \sqrt{V}$-curves of argon and methane closely resemble each other over the range of velocities investigated, which in our case was from $1 \cdot 74 \sqrt{V}$ down. to $0.3 \sqrt{V}$. The minimum $Q$ obtained for methane by Ramsauer and Kollath was $4.7 \mathrm{~cm} .{ }^{2} / \mathrm{cm} .{ }^{3}$ at a velocity of $0.62 \sqrt{V}$; our value is $4.3 \mathrm{~cm} .{ }^{2} / \mathrm{cm}^{3}$ at a velocity of $0.52 \sqrt{V}$. The minimum in our curve is a little less sharp than in the curve of Ramsauer and Kollath.

The resemblance of the $Q-\sqrt{V}$-curve of methane to that of argon would suggest at first sight that the molecule of $\mathrm{CH}_{4}$ behaves in collisions with slow electrons very much like the atom of argon. This is, how ever, by no means the case, as the following considerations show. It is a great advantage of Townsend's method that it gives information not only about the $Q-\sqrt{V}$-curve but also about the electronic temperature factor $k$, the drift velocity $W$ in the direction of the electric force $Z$, and the average fractional loss of energy in collisions between the electrons and the gas atoms or molecules. These data cannot be obtained by Ramsauer's method, which gives the $Q-\sqrt{ } V$-curve alone. In Townsend's method the shape of the $Q-\sqrt{\bar{V}}$-curve for any particular gas is essentially determined by the succession of values of $W \sqrt{ } \bar{k}$ corresponding to successive values of $Z / p$, where $p$ is the gas pressure. A comparison of the $Z / p$ - $k$-curve obtained experimentally by us for methane with the $Z / p$ - $k$-curve previously obtained by Townsend and Bailey for argon ${ }^{4}$ shows great dissimilarity. For example, for $Z / p=0.2$ the $k$-values of argon, neon, and methane are 120,62 , and 4 respectively. The same is true of the $Z / p-W$. curves : at $Z / p=0.2$ the values of the drift velocity, $W$, of argon, neon, and methane are in the ratio $3 \cdot 25: 5: 27$. It will be noticed that whereas the $k$-values decrease as we proceed from argon to methane, the $W$-values increase. It is due to this compensating effect that the values $W \sqrt{ } \bar{k}$ run fairly parallel in the case of argon and methane.

A still more marked difference between the collisions of electrons with methane molecules and argon atoms is shown by the $\lambda-\sqrt{V}$-curves for these gases. These curves indicate that of all the gases so far investigated, including inert and non-inert gases, methane and argon occupy the two extreme positions within the region $0.3 \sqrt{V}$ to $1.75 \sqrt{V}$ : the average fractional loss of energy in the collision of electrons with argon is less than in any other gas over this range. The fact that in the case of methane this loss is greater than for any

No. 3186, VoL. 126] 